\title{
A Case of Cri-du-Chat Associated with Cataracts and Transmitted from a Mother with a 4/5 Translocation*
}

\author{
HAROLD GROTSKY, LILLIAN Y. F. HSU, and KURT HIRSCHHORN
}

From the Department of Pediatrics, Division of Medical Genetics, Mount Sinai School of Medicine, New York, USA

The cat cry syndrome (cri-du-chat) was first described by Lejeune et al (1963) in a group of patients with mew-like cry and other congenital anomalies who had a partial deletion of the short arm of a B group chromosome. This partially deleted B group chromosome was subsequently found to be No. 5 by autoradiographic studies performed by German et al (1964). Other prominent manifestations of this syndrome are: low birth weight, mental retardation, failure to thrive, microcephaly, hypertelorism, epicanthal folds, antimongoloid slant, low set ears, micrognathia, and simian lines (Nusbacher and Hirschhorn, 1969).

We wish to report a child with cat cry syndrome who also has cataracts. His partially deleted number 5 chromosome was transmitted from his mother who carries a balanced reciprocal translocation $t(4 q+; 5 p-)$. To our knowledge, cat cry syndrome transmitted from this type of translocation has not been previously reported.

\section{Case Report}

J.S. (born 2 April 1969) was born to a 41-year-old gravida 2 para 0 Puerto Rican mother after a normal full-term pregnancy and delivery. There was no history of maternal rubella exposure, drug ingestion, or radiation. The father was $\mathbf{4 8}$ years of age at the time of delivery. The family history is significant in that the mother had a 6-month gestation which was still-born approximately 6 years before this delivery, and failed to conceive since then until this pregnancy. The mother has 5 healthy sibs, 4 of whom have produced normal children. One sib has not married. The father has 4 healthy children by a previous marriage. He has 3 sibs all of whom are normal and have normal children.

The child's birth weight was $2460 \mathrm{~g}$, length $49 \mathrm{~cm}$, and a chest circumference $29 \mathrm{~cm}$. He was microcephalic with a head circumference of $30 \mathrm{~cm}$. He was noted to have a high pitched mew-like cry, hypertelorism, micrognathia, partial syndactyly of the 2 nd and 3rd toes

Received 13 October 1970.

* This work was supported by USPHS Research Grant HD-02552.

8-J.M.G. 369 bilaterally, and a small phallus of approximately $1 \mathrm{~cm}$ in length.

At 8 months of age cataracts were first noted and have become progessively more prominent. During his first year of life, his head circumference has fallen progressively further below the 3 rd centile. At one year of age, his head circumference was $40 \mathrm{~cm}$. His weight has remained below the 3rd centile and at 1 year of age, he weighed $7.9 \mathrm{~kg}$. His length has remained at the 10 th centile and, at 1 year of age, was $72 \mathrm{~cm}$. At 1 year of age, he was unable to sit, showed no social response and could not follow an object.

Laboratory Data. Titres for rubella, toxoplasomosis, and cytomegalic inclusion disease in the patient and his mother were negative. Skull $x$-rays and long bone $x$-rays for rubella lines were normal.

Dermatoglyphs. The patient had a unilateral simian line on his right palm, bilateral distally located axial triradii $\left(t^{\prime \prime}\right)$, and otherwise unremarkable finger patterns ( 9 ulnar loops and 1 whorl).

The mother showed bilateral distally located triadii $\left(t^{\prime \prime}\right), 8$ ulnar loops, one arch on the left middle finger, and one radial loop on the left index finger.

The father had completely unremarkable dermatoglyphics with normal location of palmar triradii $(t)$ and 6 ulnar loops and 4 whorls on the fingers.

Cytogenetics. Chromosome studies from two peripheral leucocyte cultures revealed a modal number of 46 , with a normal male sex chromosome constitution (XY) but with one chromosome in the $\mathrm{B}$ group having a partial deletion of the short arm $(\mathrm{Bp}-$ ) (Fig. 1). A total of 32 metaphases were analysed. Autoradiographic studies with the ${ }^{3} \mathrm{H}$-thymidine added 6 hours before harvesting, showed that this B chromosome with partial deletion of the short arm was a No. 5 because of its early replicating nature.

Chromosome analyses of the mother from the peripheral leucocyte culture showed a modal number of 46 but with two structurally abnormal chromosomes in the B group, ie, one partially deleted chromosome $(\mathrm{Bp}-$ ) similar to that found in the patient, and one abnormally long chromosome with elongation of the long arm $(\mathrm{Bq}+)$. A total of 70 metaphases were analysed. Autoradiographic studies revealed that the abnormally 


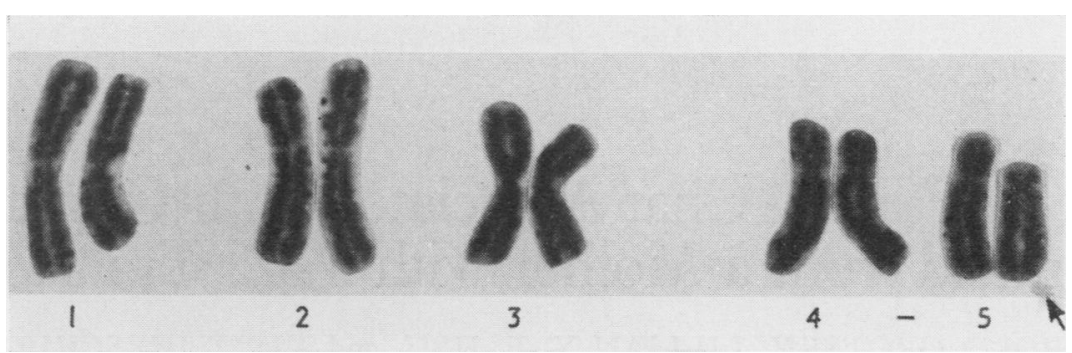

FIG. 1. Partial karyotype of $\mathrm{A}$ and $\mathrm{B}$ group chromosomes of the patient showing $5 \mathrm{p}-$.

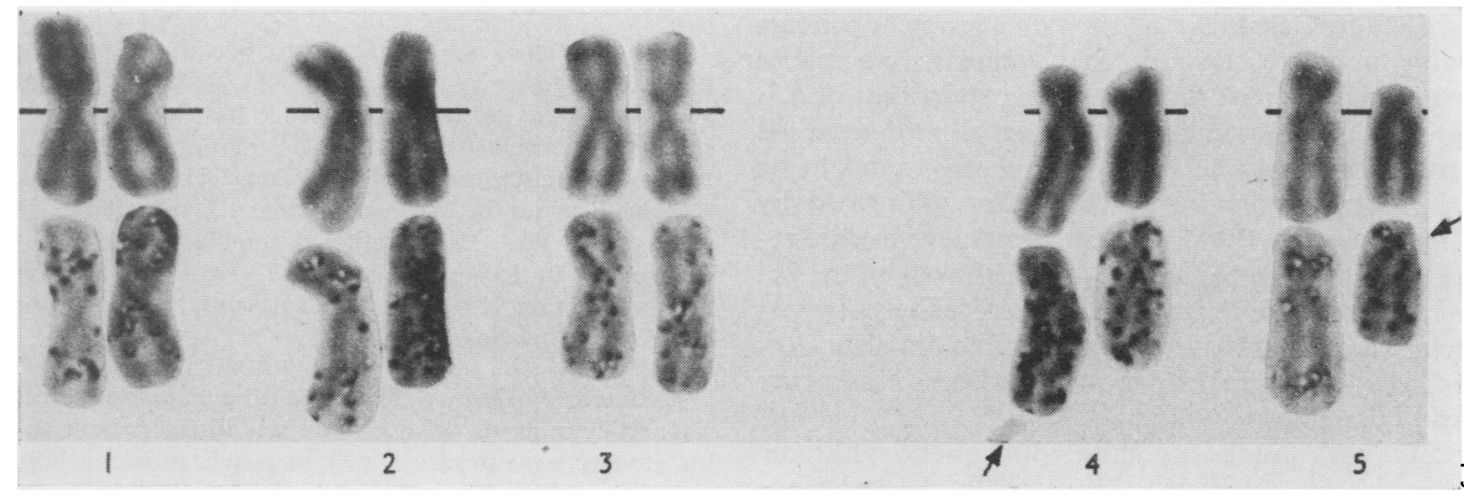

FIG. 2. Partial karyotype of the mother, showing $t(4 q+; 5 p-)$. The chromosomes were paired with the autoradiograph of each below. Arrows indicate $4 \mathrm{q}+$ and $5 \mathrm{p}-$.

long B group chromosome was a late replicating chromosome, while $\mathrm{Bp}$ - chromosome had an early replicating nature. Thus it is apparent that the mother is a carrier of a balanced reciprocal translocation between the long arm of chromosome No. 4 and the short arm of No. 5. Her karyotype, $46, \mathrm{XX}, \mathrm{t}(4 \mathrm{q}+; 5 \mathrm{p}-)$ is shown in Figure 2.

Chromosome analysis of the leucocyte culture of the father revealed a normal male karyotype $(46, \mathrm{XY})$ in 20 metaphases examined.

\section{Discussion}

Cataracts have never been described in this syndrome (Nusbacher and Hirschhorn, 1969). The possibility exists that the occurrence of cri-du-chat and cataracts in the same patient is coincidental. The probability, however, is that cataracts are an integral although rare component of the syndrome.

It is estimated that only $13 \%$ of cri-du-chat are transmitted from a parental balanced translocation (de Capoa et al, 1967). B/D and B/G parental translocations giving rise to a child with cri-du-chat have been previously reported (Reinwein and Wolf, 1965; Wolf et al, 1966; de Grouchy et al, 1965).
To our knowledge, this is the first case of cri-duchat transmitted from a parental 4/5 translocation.

It is interesting to note that the mother had a stillborn and an abnormal child. She was also unable to conceive in 6 years. It has been suggested that subfertility, abnormal children, and multiple abortions may result from a balanced structural chromosomal abnormality including translocation and inversion (structural heterozygote). In fact, parents carrying a balanced translocation have been reported to produce multiple abortions and abnormal children (Hsu et al, 1970; Kadotani et al, 1970).

\section{REFERENCES}

De Capoa, A., Warburton, D., Breg, W. R., Miller, D. A and Miller, O. J. (1967). Translocation heterozygosis: a cause of five cases of the Cri du Chat syndrome and two cases with a duplication of chromosome number five in three families. American fournal of Human Genetics, 19, 586-603.

German, J., Lejeune, J., Macintyre, M. N., and Grouchy, J. de (1964). Chromosomal autoradiography in the cri du chat syndrome. Cytogenetics (Basel), 3, 347-352.

Grouchy, J. de and Gabilan, J. C. (1965). Translocation 5/21-22 et syndrome du cri du chat. Annales de Génétique, 8, 31-38. 
Hsu, L. Y. F., Barcinski, M., Shapiro, L. R., Valderama, E., Gertner, M., and Hirschhorn, K. (1970). Parental chromosomal, aberrations associated with multiple abortions and an abnormal infant. Obstetrics and Gynecology, 36, 723-730.

Kadotani, T., Ohama, K., Sofuni, T., and Hamilton, H. B. (1970). Abberant karyotypes and spontaneous abortions in a Japanese family. Nature, 225, 735-737.

Lejeune, J., Lafourcade, J., Berger, R., Vialatte, J., Boeswillwald, M., Seringe, P., and Turpin, R. (1963). Trois cas de délétion partielle du bras court d'un chromosome 5. Comptes Rendus hebdomadaires des Séances de l'Académie des Sciences, 257, 30984000.

Nusbacher, J. and Hirschhorn, K. (1969). Autosomal anomalies in man. Advances in Teratology, 3, 1-63.

Reinwein, H. and Wolf, U. (1965). 'Cri du Chat' with 5/D translocation. Lancet, 2, 797. 1965.

Wolf, U., Reinwein, H., Gey, W., and Klose, J. (1966). Cri-duchat Syndrom mit Translokation $5 / \mathrm{D}_{2}$. Humangenetik, 2, 63-77. 